\title{
Protein expression changes in a cell system of beta-cell maturation reflect an acquired sensitivity to IL-1 $\beta$
}

\author{
K. Nielsen ${ }^{1}$, T. Sparre1, M. R. Larsen ${ }^{3}$, M. Nielsen², S. J. Fey ${ }^{2}$, P. Mose Larsen², P. Roepstorff ${ }^{3}$, J. Nerup ${ }^{1}$, \\ A. E. Karlsen 1 \\ ${ }^{1}$ Steno Diabetes Center, Gentofte, Denmark \\ ${ }^{2}$ Centre for Proteome Analysis, Odense, Denmark \\ ${ }^{3}$ Institute for Biochemistry and Molecular Biology, University of Southern Denmark, Odense, Denmark
}

\begin{abstract}
Aim/hypothesis. Type 1 diabetes mellitus (T1DM) is caused by specific destruction of the pancreatic beta cells in the islets of Langerhans. Increased sensitivity to cytokines, in particular to interleukin-1 $\beta$ (IL-1 $\beta$ ) seems to be an acquired trait during beta-cell maturation. In response to cytokines both protective and deleterious mechanisms are induced in beta cells, and when the deleterious prevail, T1DM develops. The aims of this study were to identify perturbation in protein patterns (PiPP) associated with beta-cell maturation, and compare these changes to previous analyses of IL-1 $\beta$ exposed rat islets. For this purpose, proteome analyses were carried out using a cell-line, which matures from a glucagon-producing pre-beta-cell phenotype (NHI-glu) to an insulin-producing beta-cell phenotype (NHI-ins). We have previously shown that this maturation is accompanied by acquired sensitivity to

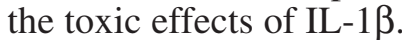

Received: 18 August 2003 / Revised: 7 October 2003

Published online: 3 December 2003

(C) Springer-Verlag 2003

A. E. Karlsen ( Steno Diabetes Center, Niels Steensensvej 2, 2820 Gentofte, Denmark

E-mail: aek@novonordisk.com

Abbreviations: T1DM, Type 1 diabetes mellitus; PiPP, perturbation in protein pattern; NO, nitric oxide; iNOS, inducible nitric oxide synthase; 2D-GE, 2 dimensional gel electrophoresis; IEF, isoelectric focusing; NEPHGE, non-equilibrium $\mathrm{pH}$-gradient electrophoresis; WF, Wistar Furth; BB, Bio Breeding; PDX-1, pancreatic duodenum homeobox 1; ASS, argininosuccinate synthetase; HSP, heat shock protein; Picot, PKC-interacting cousin of thioredoxin; JNK, Jun N-terminal kinase; VDAC, voltage-dependent anion channel; GST, glutathione-Stransferase; Mw, molecular weight; pI, isoelectric point.
Methods. 2D-gel electrophoresis was used to separate the proteins and MALDI-MS and database searches were performed to identify the proteins.

Results. During beta-cell maturation 135 protein spots out of 2239 detectable changed expression levels. Of these, 74 were down-regulated, 44 up-regulated, 16 were suppressed and 1 was expressed de novo. Using MALDI-MS, positive identification was obtained for 93 out of the 135 protein-spots revealing 97 different proteins. Of these, 22 proteins were in common with changes identified in previous proteome analysis of perturbation in protein pattern in IL- $1 \beta$ exposed rat islets. Several of the proteins were present in more than one spot suggesting post-translational modification.

Conclusion/interpretation. Several proteins and protein modifications were identified that could be critically involved in beta-cell maturation, insulin-gene expression and the acquired IL-1 $\beta$ sensitivity. [Diabetologia (2004) 47:62-74]

Keywords Beta-cell maturation · IL-1 $\beta$. proteome analysis $\cdot$ mass spectrometry $\cdot$ pathogenesis
Autoimmune Type 1 diabetes mellitus (T1DM) is caused by specific destruction of the insulin-producing beta cells in the islets of Langerhans in the pancreas [1]. During this process the islets are infiltrated with macrophages and lymphocytes, and these cells release a mixture of cytokines, such as interleukin- $1 \beta$ (IL-1 $)$, tumour necrosis factor- $\alpha$ (TNF- $\alpha$ ) and interferon- $\gamma($ IFN- $\gamma)$ to which beta cells are particularly sensitive [2]. Cytokines have been shown to induce different free radicals [3] including nitric oxide (NO), catalyzed by inducible nitric oxide synthase (iNOS), as described in the Copenhagen Model of beta-cell destruction in T1DM [4]. 
During development of the pancreas, all four endocrine cell-types ( $\alpha, \beta, \delta$ and pp cells) are believed to arise from the same stem cell [5] and this specialization is dependent upon activation of different transcription factors $[6,7,8,9]$. Since sensitivity to cytokines, free radicals and toxic chemicals is exquisite for the beta cell, this could reflect an acquired trait during the maturation of stem cells into mature insulin producing beta cells. We therefore hypothesize, that PiPP leading to susceptibility to IL-1 $\beta$-damage is a consequence of beta-cell maturation. Here we address this hypothesis by using a glucagon producing pre-beta-cell cell line (NHI-glu), which following in vivo passage as a subcutaneous tumour in a rat, was re-established as an insulin producing beta-cell line (NHIins) $[10,11]$. Our previous analyses of these two phenotypes showed that this maturation process was accompanied by an acquired sensitivity to the toxic effects of IL-1 $\beta$ [12]. Hence, the aim of our study was to characterize by proteome analysis [13, 14, 15] changes in protein expression accompanying the final maturation from the glucagon positive and IL-1 $\beta$ resistant pre-beta-cell phenotype to the insulin positive and IL-1 $\beta$ sensitive beta-cell phenotype and to relate these data to our previous analysis of PiPP in IL-1 $\beta$ exposed rat islets. $[14,16]$.

\section{Materials and methods}

Cell culture. The NHI-cell system [12] is based on the subclone NHI-glu derived from the glucagon-producing MSL-G2 culture [17]. Following in vivo passage by transplantation into syngeneic NEDH rats, the NHI-glu cells mature into insulinomas $[10,18]$. The insulinomas re-established in vitro have an insulin-producing phenotype (NHI-ins) for prolonged periods of time [19], closely resembling beta cells with respect to the mRNA expression profile [20].

The two NHI-phenotypes were cultured in RPMI 1640 Glutamax (GibcoBRL Life Technologies, Paisley, Scotland, UK) supplemented with $10 \%$ FCS (GibcoBRL Life Technologies) and $1 \%$ penicillin/streptomycin (GibcoBRL Life Technologies) at $37^{\circ} \mathrm{C}$ in a $5 \% \mathrm{CO}_{2}$ atmosphere in four independent experiments. For metabolic labelling $2 \times 10^{5}$ cells/well were set up in 24-well plate (Costar, Cambridge, Mass., USA) containing $3 \mathrm{ml}$ media. To prepare a large amount of protein for preparative gels and MS, cells were cultured in $50 \mathrm{ml}$ tissueculture flasks ( $10^{7}$ cells/bottle) for 4 days.

Cell labelling. Cells used for 2D-GE analysis were cultured for $44 \mathrm{~h}$ and then washed twice in HBSS and labelled for $4 \mathrm{~h}$ in $250 \mu \mathrm{l} /$ well methionine-free Dulbecco's modified Eagle's medium (DMEM) [21] with $10 \%$ dialyzed NHS and $18.5 \mathrm{MBq} / \mathrm{ml}$ $\left[{ }^{35} \mathrm{~S}\right]$-methionine (SJ 204 Amersham International, Amersham, UK). After labelling the cells were washed twice in HBSS and lysed with $100 \mu \mathrm{l}$ lysis buffer $(8.5 \mathrm{~mol} / \mathrm{l}$ urea, $2 \%$ nonidet P-40, $5 \%$ 2-mercaptoethanol and $2 \%$ carrier ampholytes, $\mathrm{pH}$ range 7-9) and stored at $-80^{\circ} \mathrm{C}$.

Determination of [35S]-methionine incorporation. $\left.{ }^{[35} \mathrm{S}\right]-$ methionine incorporation was quantitated in duplicate by adding $10 \mu \mathrm{BSA}\left(0.2 \mu \mathrm{g} / \mathrm{ml}\right.$ in $\left.\mathrm{H}_{2} \mathrm{O}\right)$ as a protein-carrier to $5 \mu \mathrm{l}$ of each sample diluted 1:10 with lysis buffer, followed by $0.5 \mathrm{ml}$ of $10 \%$ TCA. This was left to precipitate for $30 \mathrm{~min}$ at $4{ }^{\circ} \mathrm{C}$ before being filtered through $0.25 \mu \mathrm{m}$ HAWP filters (Millipore) presoaked in BSA-saturated $10 \%$ TCA. The filters were washed twice with $1 \mathrm{ml} \mathrm{BSA}$-saturated $10 \%$ TCA, once with ethanol, dried and placed into scintillation liquid for counting.

$2 D$-gel electrophoresis. The procedure was as previously described [22]. Briefly, first-dimensional gels contained 4\% acrylamide, $0.25 \%$ bisacrylamide and carrier ampholytes. An equal number of counts $\left(10^{6} \mathrm{cpm}\right)$ of each sample were applied to the gels. The samples were analyzed on both isoelectric focusing (IEF; $\mathrm{pH}$ 3.5-7.0) and non-equilibrium $\mathrm{pH}$-gradient electrophoresis (NEPHGE; pH 6.5-10.5) gels. Second-dimension gels contained $12.5 \%$ acrylamide and $0.063 \%$ bisacrylamide run overnight at $20^{\circ} \mathrm{C}$. After electrophoresis, gels were fixed with Amplify (Amersham) before being dried. The gels were exposed to a PhosphoImage screen and the protein-pattern was scanned on a PhosphorImager (ADC 70 AGFA, Belgium). The resulting approximately $8 \mathrm{MB}$ images were converted to 16-bit tiff images for image analysis.

Computer-assisted analysis. Computer analysis was carried out using the BioImage program 2D-Analyzer (version 6.1; Genomic Solutions, Ann Arbor, Mich., USA). The computer program assists in the matching of the spots among the eight independent gels, four from each phenotype, into a composite image followed by manual editing (Fig. 1). All protein spots that were marked were then re-evaluated to ensure that the boundaries assigned to the protein spots were correct and that no matching errors between the gels had been made. Significant changes in percent integrated optical density (IOD) between individual spots in the NHI-glu compared with the NHIins phenotype were determined using a double-sided nonpaired Student's $t$-test comparing four independent experiments from each phenotype. Changes with a $p$ value less than 0.01 were accepted as being statistically significant.

Protein characterization. For preparative purpose, a pool of $2 \times 10^{7}$ cells were prepared and separated on $2 \mathrm{D}$-gels as described above. For localization of the spots, a sample of $10 \%$ of the cells was radioactively labelled to be used as a tracer as previously described. We ran six gels of each cell type, and loaded each with $200 \mu \mathrm{g}$ of non-labelled protein and $4 \times 10^{6} \mathrm{cpm} / \mathrm{gel}$ of $\left[{ }^{35} \mathrm{~S}\right]$-methionine labelled protein per gel.

Protein identification using matrix assisted laser desorption/ionization mass spectrometric (MALDI-MS) peptide mass mapping. Protein spots of interest were obtained by cutting them out of the dried gel using a clean scalpel. All 135 selected spots could technically be cut out of the preparative-gels for protein identification. The proteins were enzymatically digested in the gel as described [23] with minor modifications [24]. In short, the excised gel plugs were washed in $50 \mathrm{mmol} / \mathrm{l}$ $\mathrm{NH}_{4} \mathrm{HCO}_{3}$ /acetonitrile $(60 / 40)$ and dried by vacuum centrifugation. Digestion buffer $\left(50 \mathrm{mmol} / \mathrm{l} \mathrm{NH}_{4} \mathrm{HCO}_{3}\right)$ containing endoproteinase lys-C (8 ng/ $\mu$ l, Calbiochem, San Diego, Calif., USA) was added to the dry gel pieces and incubated on ice for $1 \mathrm{~h}$ for re-swelling. After removing the supernatant, an additional 20-40 $\mu \mathrm{l}$ digestion buffer was added, and the digestion was continued at $37^{\circ} \mathrm{C}$ for $4-18 \mathrm{~h}$. The peptides were desalted and concentrated prior to MALDI-MS as previously described [15]. The peptides were deposited directly onto the MALDI target by elution with matrix solution [ $\alpha$-cyano-4-hydroxy cinnamic acid in $70 \%$ acetonitrile/29.9\% water/0.1\% TFA (20 g/l)]. MALDI-MS analysis was carried out using a Voyager STR instrument (PerSeptive BioSystems, Framingham, Mass., 


\section{D-gels of the NHI-glu phenotype}

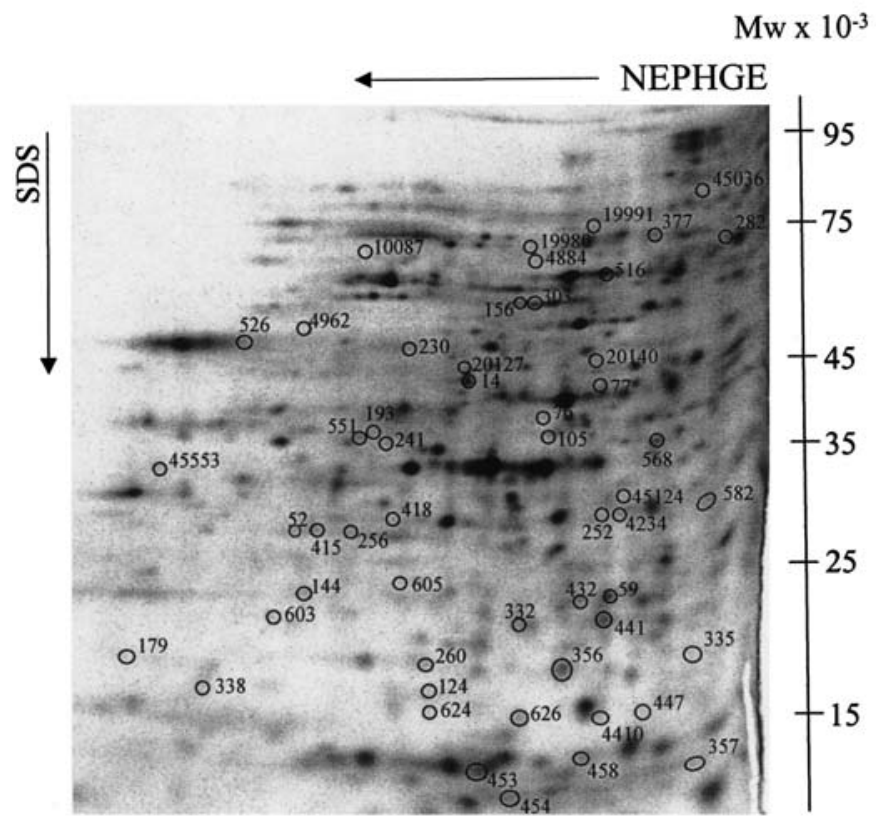

Fig. 1. Sections of the NEPHGE and the IEF 2D-gels of the NHI-glu phenotype covering the spots of changed expression level. The spot number refers to the match number assigned by the Bio Image computer program and used throughout the manuscript

USA) equipped with delayed extraction. Spectra were obtained in reflector positive mode using an accelerating voltage of $20 \mathrm{kV}$. Protein identification was done by searching the peptide mass maps in a comprehensive non-redundant protein sequence database (nrdb, European Bioinformatics Institute, Hinxton, Cambridge, UK) using the ProFound software (http://129.85.19.192/profound_bin/WebProFound.exe ) with a mass accuracy of below $50 \mathrm{ppm}$ [25]. Both first and second pass searches were carried out and the validation of the individual protein identifications was carried out [25]. In short, the Z-score described in the ProFound software was used as the primary evaluation of a positive identification, supported by information on sequence coverage, induced oxidation of methionine residues and terminal sequence tags, For identifications with a Z-score between 1.2 and 2.0 a careful evaluation including information on protein molecular weight together with the above-mentioned parameters were taken into account.

Determination of $M w$ and $p I$. Determination of the $\mathrm{Mw}$ and $\mathrm{pI}$ of all the spots were done by cutting 17 spots with high density form the NEPHGE 2D-gels and 24 spots of the IEF 2D-gels. Identification of the spots was carried out by MS and the Mw and $\mathrm{pI}$ values, from the identified proteins, were used as markers in the Bioimage Program to calculate the Mw and $\mathrm{pI}$ values for all the spots in the gel. Theoretical pI and Mw were calculated for all the identified proteins using the 'Compute $\mathrm{pI} / \mathrm{Mw}$ tool' at the ExPASy Molecular Biology Server (http://www. expasy.ch/tools/pi_tool.html ) taking into account any posttranslational cleavage known.

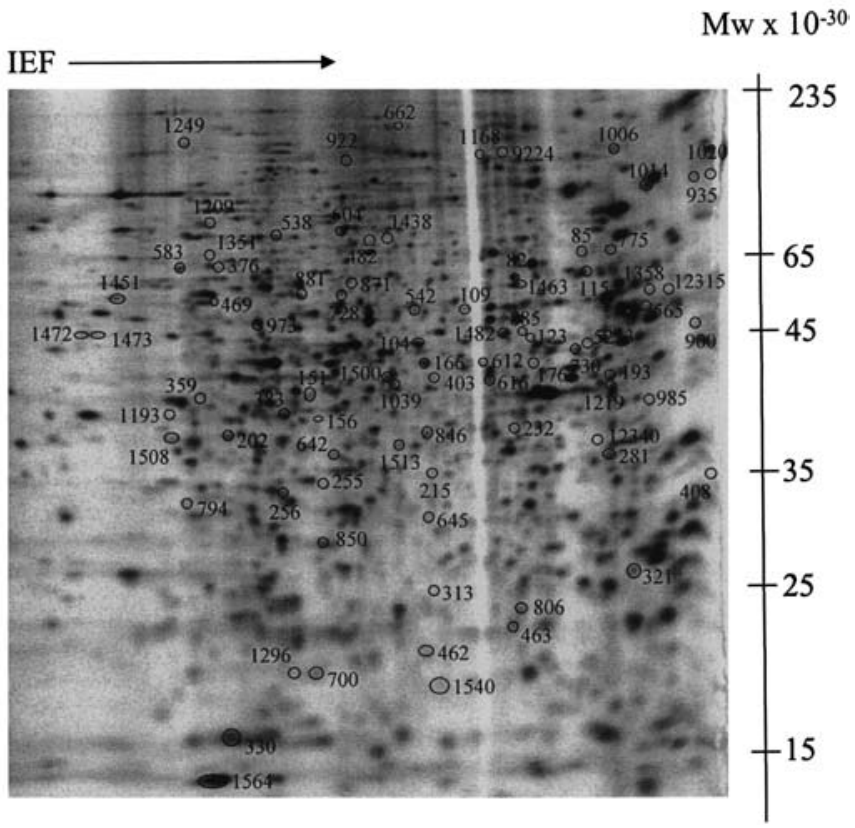

\section{Results}

Expressions of 135 (53 spots from the NEPHGE 2Dgels and 82 spots from the IEF 2D-gels) out of 2239 reproducibly detectable spots were significantly $(p<0.01)$ changed when samples of NHI-glu and NHIins were compared by 2D-GE. A total of 97 different proteins were unambiguously identified in 94 out of the 135 spots by mass spectrometry (a success rate of $70 \%$, Table 1). The remaining 41 spots (Table 2) yielded either good mass spectra but no matches in the databases (17 spots), weak spectrum but no protein identification (19 spots) or no spectra at all (5 spots).

Our data show that at least $37 \%$ of the proteins identified might be post-translationally modified, since they were either found in more than one spot on the 2D-gel (22 proteins) or their observed and calculated theoretical $\mathrm{Mw}$ and/or $\mathrm{pI}$ were in discordance (19 proteins, see below). A total of five proteins were overlapping between these two groups. We found that 15 proteins were present in two spots each (ATP synthase $\alpha$ chain, $\gamma$-enolase, pyruvate kinase M1 isozyme, flag structure-specific endonuclease, ezrin, T-complex protein $1 \varepsilon$ and $\gamma$, protein disulfide isomerase, Hsc70-ps1, alpha-2-macroglobulin receptor-associated protein, dihydropyrimidase-related protein 2 , voltage-dependent anion-selective channel protein 1 , sorting nexin 6 , septin-like protein and Erp 44). Furthermore six proteins were present in three spots each (fructose-bisphosphate aldolase A, T-complex protein $1 \zeta$, probable protein disulfide isomerase ER-60, P60 protein, voltage-dependent anion-selective channel protein 2 and 26S protease regulatory subunit). Finally, one protein was present in four spots (78 KDa glucose regulated protein). Major inconsistencies were found between observed 


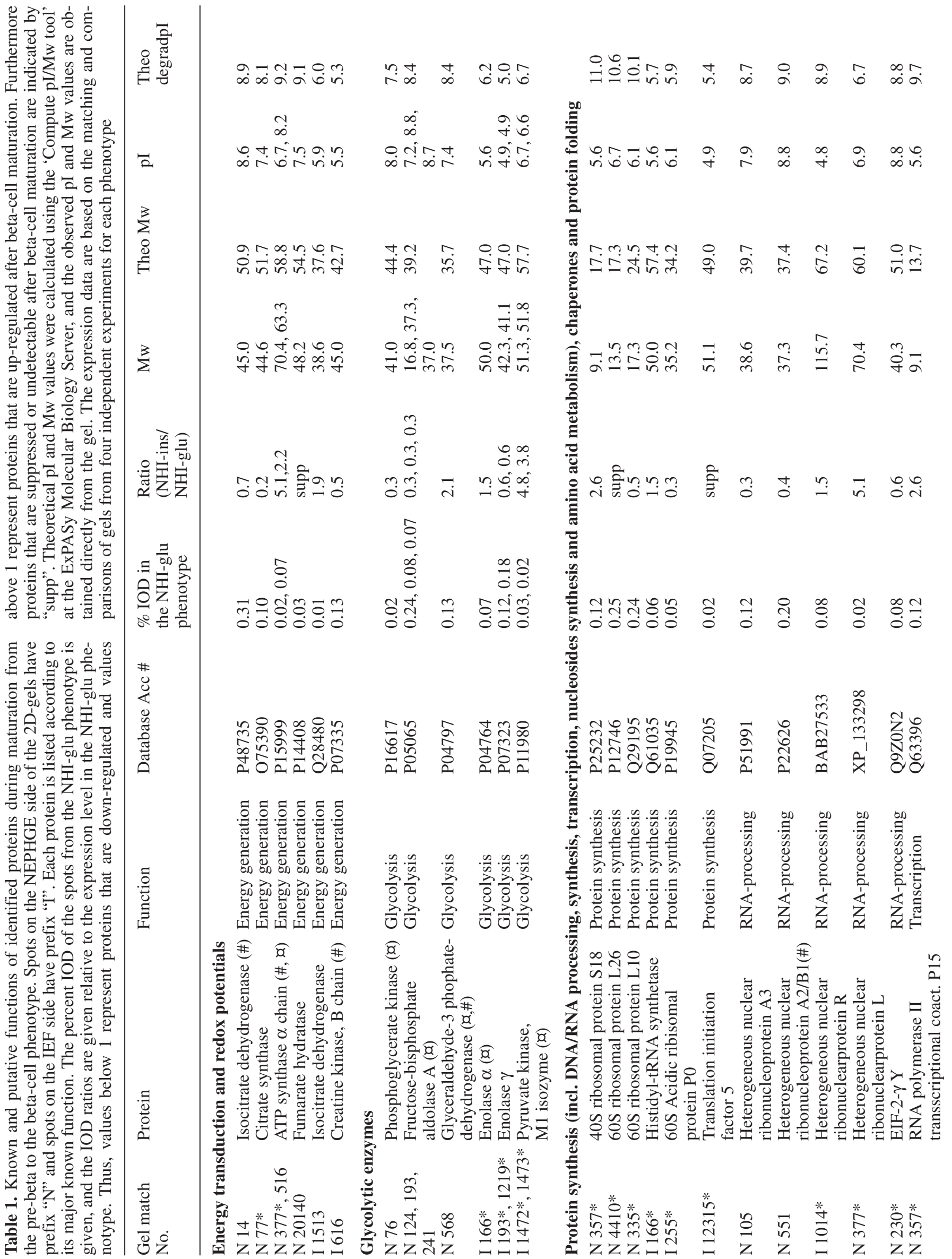


K. Nielsen et al.:

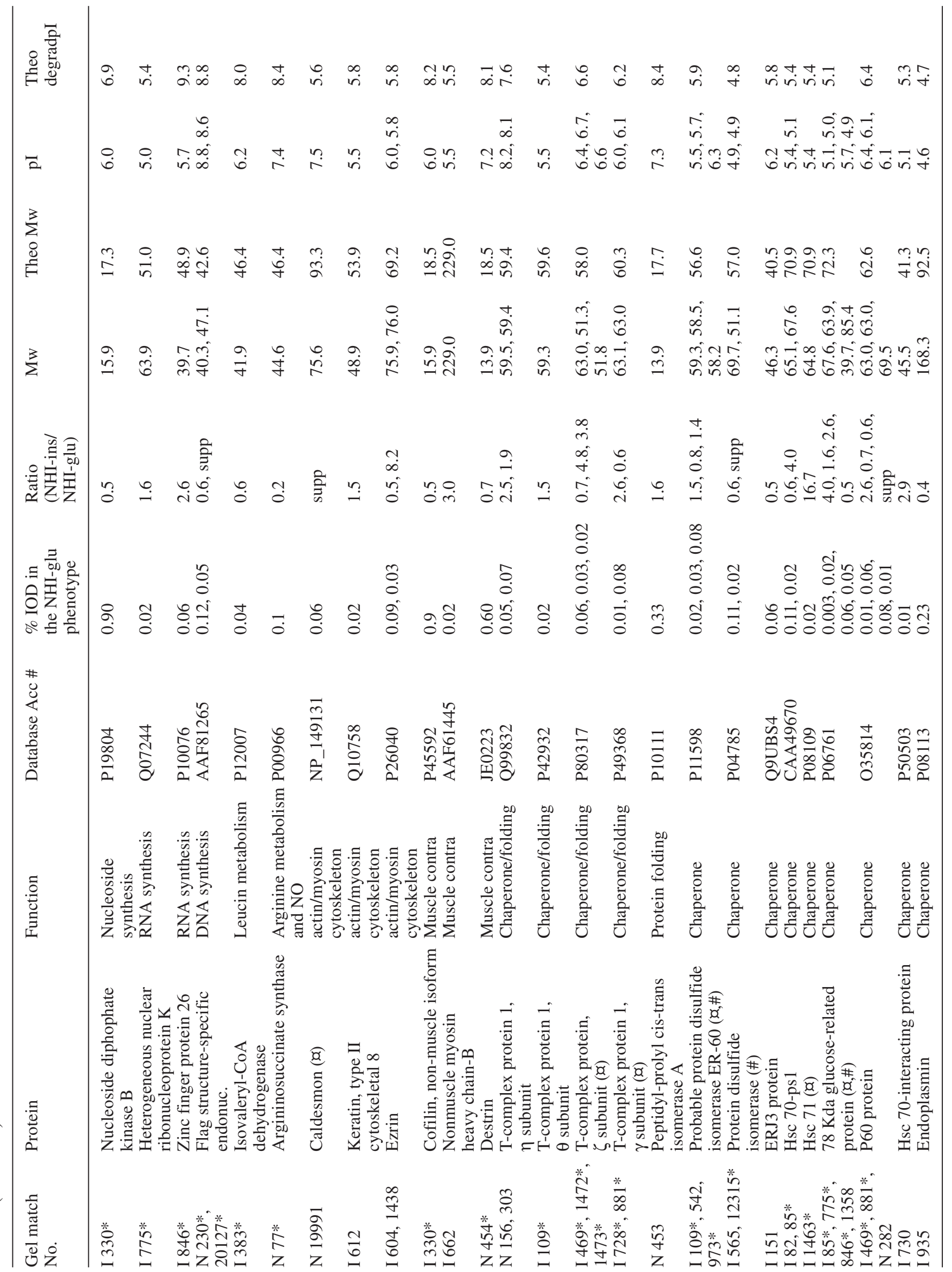




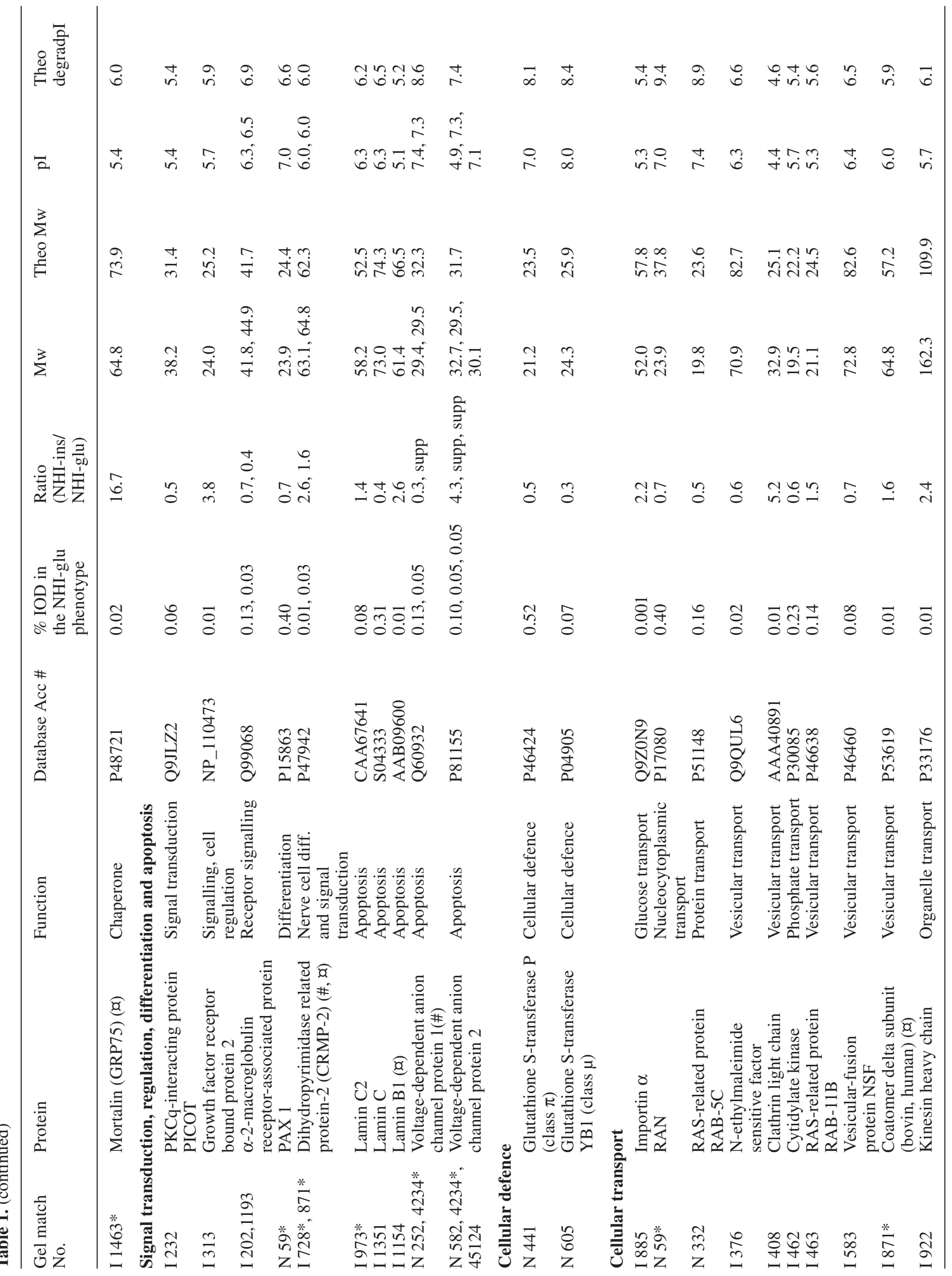




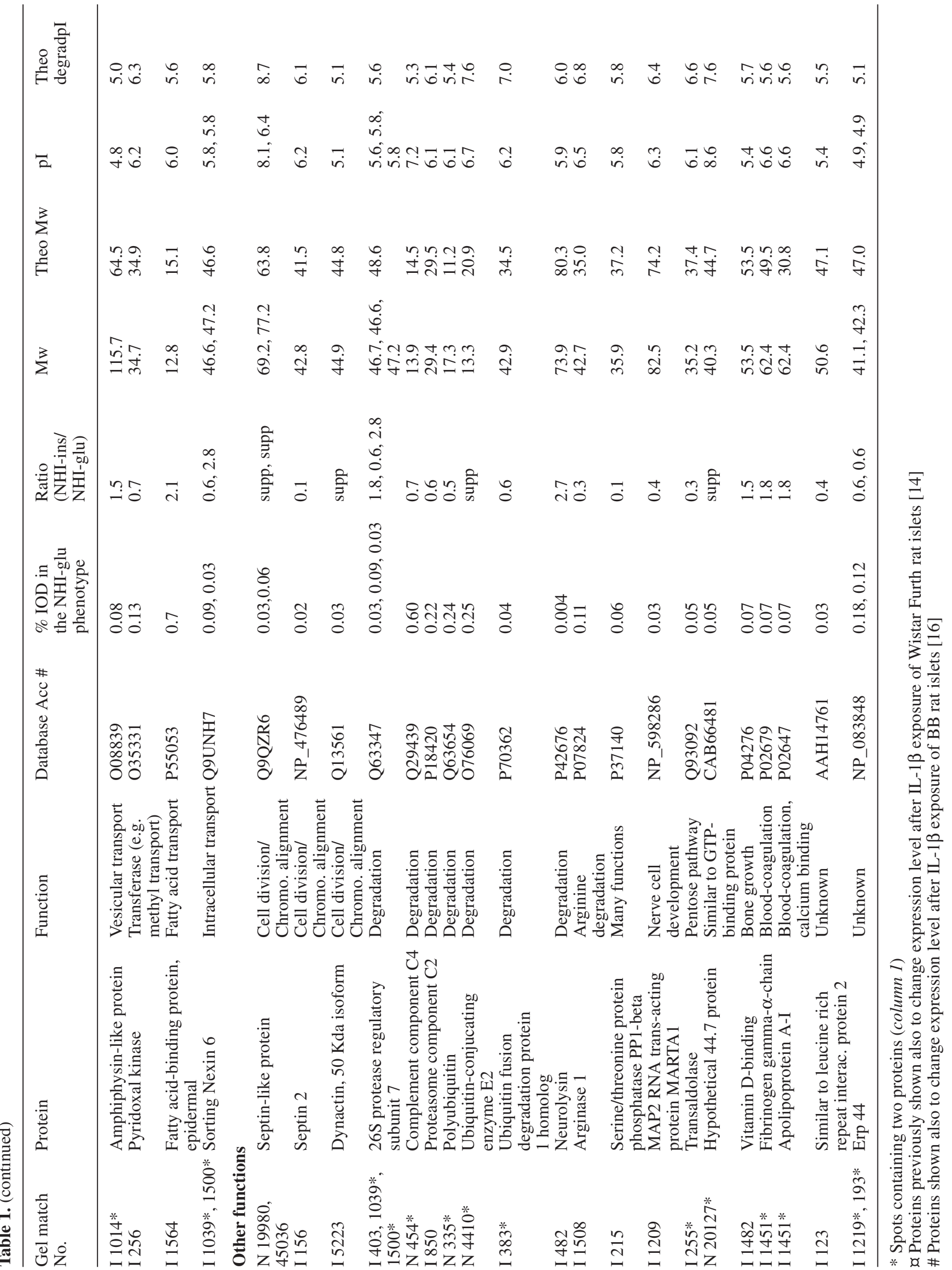


Table 2. Unidentified protein spots with statistically significant changed expression level after beta-cell maturation are shown. The percent IOD of the spots in the NHI-glu phenotype are given and the IOD ratios are given relative to the expression level in the NHI-glu phenotype. Furthermore, proteins that are sup- pressed or undetectable after beta-cell maturation are indicated by "supp". One protein only expressed in the beta-cell phenotype is indicated by "de novo". Observed pI and Mw values obtained directly from the gel are given

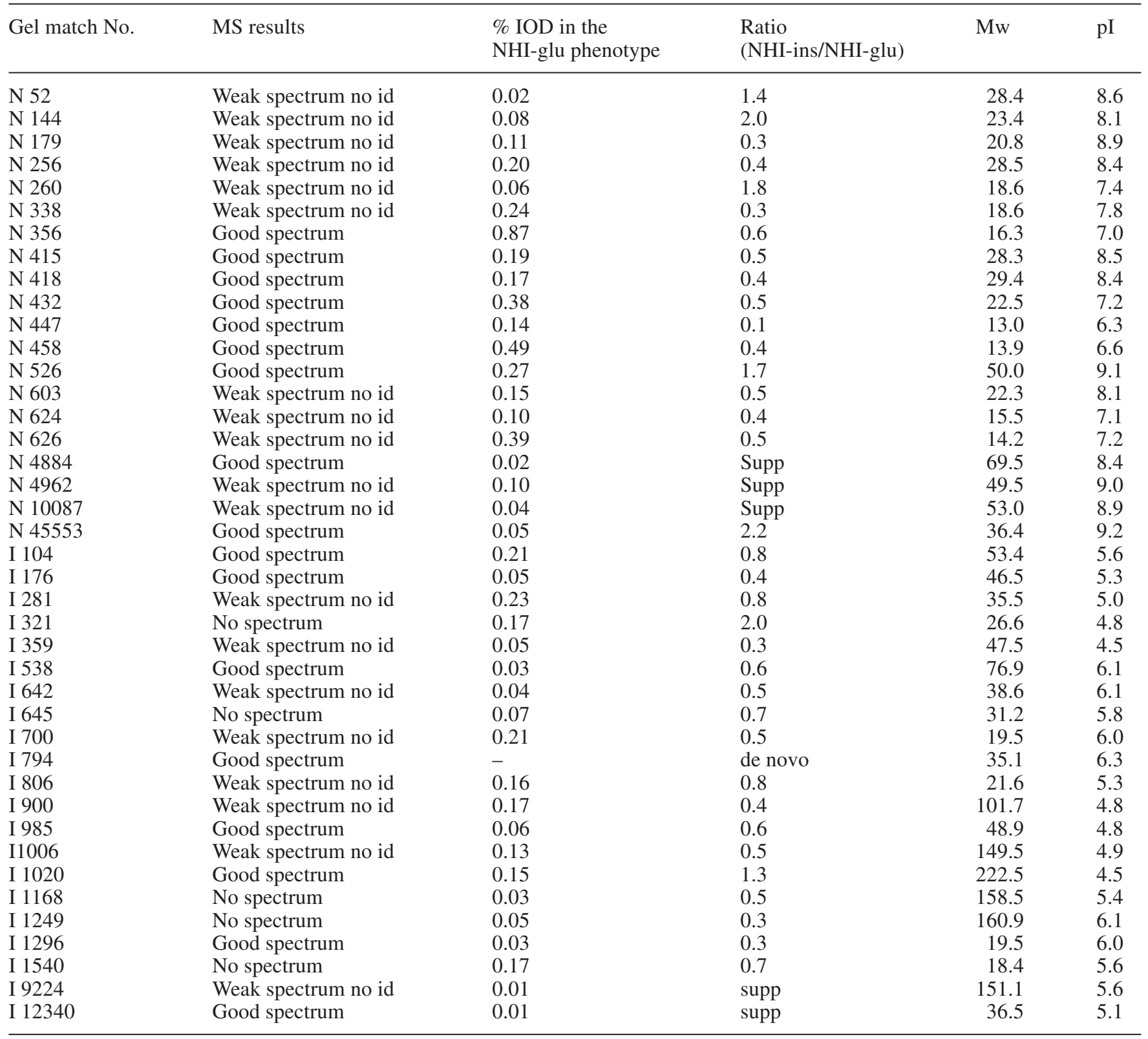

and calculated theoretical Mw and/or pI, for 19 protein-spots (20\%) (NEPHGE 59, 124, 332, 335, 357, 377, 454, 582, 4410, 19991, 20140, 45036 and IEF $330,376,846,935,922,1014,1451)$. These inconsistencies could reflect post-translational modifications.

Some spots (33 spots) contained two identified proteins (*Table 1): NEPHGE 59, 77, 230, 335, 357, 377, 454, 4234, 4410, 20127 and IEF 85, 109, 166, 193, 255, 330, 383, 469, 728, 775, 846, 871, 881, 973, 1014, 1039, 1219, 1451, 1463, 1472, 1473, 1500 and 12315. The identified proteins have been assigned in seven groups according to their major known or puta- tive functions allowing easy comparison with previous publications on PiPP of IL-1 $\beta$ exposed rat islets [14, 16]: (i) energy transduction and redox potential, (ii) glycolytic enzymes, (iii) protein synthesis, chaperones and protein folding, (iv) signal transduction, regulation, differentiation and apoptosis, (v) cellular defence, (vi) cellular transport, (vii) other functions. The function and possible importance for beta-cell maturation and T1DM pathogenesis are discussed below for selected proteins, including the 22 proteins in common with our previous analysis of PiPP in IL- $1 \beta$ exposed rat islets $[14,16]$. 


\section{Discussion}

Substantial research has been carried out to characterize the molecular mechanisms involved in the development of the pancreatic beta cells. It is generally believed that the endocrine, exocrine and ductal cell types are derived from endodermal cells [5]. Several studies have shown that the endocrine stem cell require several specific transcription factors to mature into single-hormone-expressing cells $[6,7,8,9]$. The pancreatic duodenum homeobox 1 (PDX-1) has been shown to be important both for pancreas development [26] and subsequent maturation of the endocrine cells [27], whereas later in the mature islets PDX-1 expression is restricted to the insulin-producing beta cells [8]. Another transcription factor, Nkx-6.1, is important for maturation of the insulin-producing beta cells [8], whereas Brain-4 is important for maturation of the glucagon-producing $\alpha$-cells [7]. Previous analysis of mRNA gene expression profiles by semi-quantitative multiplex RT-PCR of the two NHI-phenotypes used in this study, grown under the same conditions, showed that several genes associated with late stages of betacell maturation, such as PDX-1 were expressed in both phenotypes, whereas Nkx-6.1 was restricted to the beta-cell phenotype [20]. We showed that maturation into the beta-cell phenotype was accompanied by insulin gene expression and an acquired susceptibility to toxic effects of IL-1 $\beta$, not seen in the pre-beta-cell NHI-glu phenotype [12]. Proteome analyses of the two phenotypes could therefore identify proteins and pathways important for beta-cell maturation and the acquired IL-1 $\beta$ sensitivity.

High resolution 2D-gel technology can efficiently separate thousands of proteins. Statistical analysis of the expression pattern of the NHI-glu and NHI-ins phenotypes allowed us to separate a small group of 135 protein spots, which were differentially expressed between these phenotypes. Subsequent MALDI-MS identified the majority of the proteins $(70 \%)$ in these protein spots using available protein or translated nucleotide sequence databases. Compared to transcriptome analyses of mRNA expression, proteome analysis offers the possibility to quantitate changes in protein expression and to identify post-translational protein modifications, such as phosphorylation [15]. Post-translational modifications are often required for the functional activation of a protein or a protein complex [28], and indeed the importance of these modifications in the beta-cell maturation process is suggested by our finding that $37 \%$ of the identified proteins are present either in more than one spot, or exhibited modified mobility. Several of the other proteins might also be modified in more subtle ways. The nature of the post-translational modifications observed was not studied as part of this study. Thus, currently our data provide information on changes in protein expression profiles during beta-cell maturation. Future analyses will allow identification of the precise mechanisms as well as the functional relevance responsible for these changes.

Due to the high sensitivity of the MALDI-MS technique, 33 spots were found to contain two proteins $(34 \%)$. One study has described in detail how one spot is able to contain more than one protein [29]. In short, this could be due to overlapping protein bands or comigration in polyacryamide gel bands due to SDSPAGE limited resolving power or contamination with cytokeratins. This is important to note, since it is therefore presently not possible to say which protein in the protein spot in question actually changed expression level during the beta-cell maturation process. Future analysis using zoom gels covering narrow $\mathrm{pH}$ ranges with considerably higher resolution could resolve this [30]. Another limitation in proteome analysis is that only the proteins that are metabolically labelled with methionine under the present experimental conditions and are within the detectable $\mathrm{pI}$ and $\mathrm{Mw}$ ranges could be identified. Therefore proteins (e.g., pro-insulin and insulin) below a Mw of $12 \mathrm{kDa}$ are not detected.

The protein spots that changed expression levels after maturation into the beta-cell phenotype are grouped in Table 1 according to their known or putative functions. Similar group assignments were recently used in the description of protein changes in rat islets exposed to IL-1 $[14,16]$. It is beyond the scope of our study to discuss in detail the possible role of all identified proteins. Hence, only proteins previously shown to be influenced by IL-1 $\beta[14,16]$, and/or relevant for beta-cell maturation or beta-cell destruction are discussed.

We have previously shown that IL-1 $\beta$ influences PiPP in islets of Langerhans $[13,14,16]$. PiPP could reflect up- or down-regulation of protein expression levels and/or gel-position shifts resulting from posttranslatory modifications. Consequently, when in this paper the expression level of a protein is described as up- or down-regulated, this could reflect changes in the expression level of the native protein (including alterations in protein synthesis and degradation) or expression changes in a modified form of that protein. Therefore protein expression changes in common between beta-cell maturation and IL-1 $\beta$ exposed WF rat islets [14] and BB rat islet [16] (Table 1, $\propto$ and \#, respectively) could reflect both native or modified forms of the protein. Of the 97 proteins of changed PiPP reflecting maturation into the beta-cell phenotype identified in this study, the expression pattern of 26 of these was previously shown to be influenced by IL-1 $\beta$ in rat islets. Of these, 16 were identified in IL$1 \beta$ exposed WF rat islets [14] and 10 in IL-1 $\beta$ exposed BB rat islets [16], representing five of the common pathways (Table 1). Of these 26 proteins, only four (ATP synthase alpa chain, glyceraldehyde-3 phosphate-dehydrogenase, probable protein disulfide 
isomerase ER-60 and $78 \mathrm{Kda}$ glucose-regulated protein) were common in all three studies.

Due to the nature of the in vitro and in vivo metastasing cell-lines used in the present experiments, it cannot be excluded that proteins involved in cell-proliferation and cell-transformation might also be included in Table 1.

Energy transduction and redox potentials. Protein spots involved in the Citric acid cycle (such as isocitrate dehydrogenase, citrate synthase and fumarate hydratase) were down-regulated or suppressed after beta-cell maturation, suggesting decreased ATP production. In contrast ATP synthase $\alpha$ chain and a different form of isocitrate dehydrogenase were highly up-regulated. ATP synthase $\alpha$ chain, creatine kinase B and isocitrate dehydrogenase were also changed after IL- $\beta$ exposure of rat islets $[14,16]$. IL-1 $\beta$ has an inhibitory effect on the mitochondrial energy production in islets [31], and IL-1 $\beta$ exposure of rat islets showed downregulation of several proteins involved in energy generation $[14,16]$.

Glycolytic enzymes. During beta-cell maturation six glycolytic enzymes changed expression level. Of these, five protein spots were also changed in rat islets after IL-1 $\beta$ exposure ( $\alpha$, \# Table 1$)$. The functional relevance of the glycolytic pathway in insulin production still needs to be elucidated, since it has previously been shown that IL-1 $\beta$ does not affect the activity of any glycolytic enzyme [32]. However, it has been reported that insulin and cellular ATP levels regulate both the activity and synthesis of several glycolytic enzymes [32].

Protein synthesis, chaperones and protein folding. Proteins involved in protein synthesis were generally down-regulated after maturation of the beta-cell phenotype (the first six proteins in this group, Table 1). IL-1 $\beta$ has been shown to inhibit gene transcription and protein synthesis $[13,33]$ and to decrease preproinsulin biosynthesis in particular [34]. Therefore, a global decrease in protein synthesis could reduce the capacity of a beta cell to survive IL-1 $\beta$ exposure.

Citrullinaemia is an autosomal disorder of the urea metabolism characterized by high circulating levels of citrulline as a result of a deficiency in the activity of the urea cycle enzyme argininosuccinate synthetase (ASS) [35]. In addition, mutations in ASS cause high levels of citrulline. The expression level of ASS was significantly $(p<0.0001)$ lower in the beta-cell phenotype compared to the pre-beta-cell phenotype. This could result in increased levels of citrulline in beta cells. Beta-cell sensitivity to IL-1 $\beta$ is in part mediated through iNOS expression. iNOS converts arginine and oxygen to citrulline and NO [36]. Arginine might be provided by uptake from the extracellular fluid, by intracellular protein degradation or by synthesis from citrulline [37]. Thus, it is conceivable that the downregulation of ASS expression results in increased levels of citrulline in beta cells that in turn could induce higher intra-cellular levels of arginine. The increased pool of arginine could then serve as substrate for iNOS and result in increased production of NO [37]. However, our previous analyses have shown that despite the different sensitivity to IL- $1 \beta$, no significant difference in IL-1 $\beta$ induced NO production could be detected between the two phenotypes [12]. Nevertheless, it has been shown that IL-1 $\beta$ induces the citrulline-NO cycle in beta cells, and that extracellular arginine or citrulline is required for NO production [38]. Furthermore, the arginine level has been shown to be increased in IL-1 $\beta$ exposed beta cells [38]. Thus, it is conceivable that the beta-cell phenotype could contain increased concentrations of arginine due to low ASS expression as an acquired trait occurring during betacell maturation.

During beta-cell maturation seven protein spots involved in the formation and maintenance of the actin/myosin cytoskeleton changed expression level. One example is caldesmon also shown to be downregulated in IL-1 $\beta$ exposed rat islets [14]. Whether this influences beta-cell stability and IL-1 $\beta$ induced toxicity is yet unknown.

The remaining 15 proteins of this group are all involved in chaperone functions and/or protein folding. The $\zeta$ and $\gamma$ subunits of the T-complex protein-1 were also changed in WF rat islets after IL-1 $\beta$ exposure ( $\alpha$; Table 1) [14]. This complex is involved in molecular chaperoning and in the production and folding of native actin and tubulin [39]. We identified two proteins found in more than one spot (probable protein disulfide isomerase ER-60 and protein disulfide isomerase) specifically involved in the re-arrangement of both intra-chain and inter-chain disulfide bonds in proteins to form native protein structures. Interestingly, spots containing these two proteins were also previously shown to change expression levels in rat islets exposed to IL-1 $\beta[14,16]$.

Of the heat shock protein spots (HSPs) eight changed their level of expression after beta-cell maturation and several of these also in response to IL-1 $\beta$ (Table $1 ; \mathfrak{a}, \#)$. HSPs function as molecular chaperones assisting in protein folding, transport, translocation and degradation [40], and could have protective functions against exposure to several damaging stimuli, such as heat [41], cytokines [42] and NO [43]. Furthermore, lower expression levels of HSP have been shown in streptozotocin induced diabetic rats [44].

Signal transduction, regulation, differentiation and apoptosis. A protein spot containing PKC-interacting cousin of thioredoxin (PICOT), a Jun N-terminal kinase (JNK) inhibitor [45], was down-regulated during beta-cell maturation. JNK is activated in response to different stress factors such as cytokines, heat and oxi- 
dative compounds. Dependent upon the type of stimulation, signalling through JNK activates programmed cell death (apoptosis), differentiation/proliferation or tumour development [46], and has been shown to be critically involved in IL- $1 \beta$ mediated beta-cell destruction [47].

Apoptosis plays an important role during cell maturation [48]. Apoptosis is characterized by a set of cellular events including cell shrinkage, chromatin condensation and DNA fragmentation. Many factors have been shown to be involved in this process [49]. Toxic levels of cytokines have been shown to induce apoptosis $[50,51]$. In line with this, a cleavage product of lamin A was up-regulated after IL- $1 \beta$ exposure of rat islets in vitro [14]. After maturation of the beta-cell phenotype protein spots containing lamin $\mathrm{B} 1$ and $\mathrm{C} 2$ were up-regulated. Proteolysis of lamins, the major structural proteins of the nuclear envelope, are observed in cells undergoing apoptosis [52]. The relevance of this in relation to beta-cell sensitivity to IL- $1 \beta$ is not clear. However, it has been shown that inhibitors of lamin cleavage prevent apoptosis [53]. Voltage-dependent anion channel (VDAC) 1 was down-regulated while VDAC 2 was up-regulated after beta-cell maturation. VDAC 1 was also changed after IL- $1 \beta$ exposure of rat islets [14]. VDAC proteins form pores in the outer mitochondrial membrane serving as the major permeability pathway for metabolite flux between the cytoplasm and the mitochondria [54]. Pro-apoptotic proteins Bax and Bak bind to VDAC channels and induce apoptosis by releasing cytochrome $\mathrm{C}$, whereas the anti-apoptotic protein bcl- $\mathrm{x}_{\mathrm{L}}$ closes the VDAC channels and inhibits apoptosis [55].

Cellular defence. Gluthatione-S-tranferase (GST) is involved in the glutathione pathway where gluthathione peroxidase and GST work together with glutathione in the decomposition of hydrogen peroxide $\left(\mathrm{H}_{2} \mathrm{O}_{2}\right)$ or other organic hydroperoxides [56]. In mammalians, GSTs are divided into six classes $(\alpha, \mu, \kappa, \theta$, $\pi$ and $\sigma$ ). Protein spots containing GST (class $\pi$ and $\mu$ ) were both down-regulated during beta-cell maturation, suggesting that the beta-cell phenotype has impaired ability to reduce $\mathrm{H}_{2} \mathrm{O}_{2}$ compared to the pre-beta-cell phenotype. This reduction in cellular defence was also seen in the IL- $1 \beta$ exposed BB rat islet [16], since glutathione synthase was down-regulated. This is in line with previous analysis showing an impaired ability of islet beta cells to reduce $\mathrm{H}_{2} \mathrm{O}_{2}$ [57]. Glutathione has been shown to protect a human insulinoma cell-line against the toxic effects of tumour necrosis factor $\alpha$ $(\mathrm{TNF}-\alpha)$ [58], and together with catalase, glutathione peroxidase protects RIN cells against $\mathrm{H}_{2} \mathrm{O}_{2}$, reactiveoxygen species and cytokines [59].

Cellular transport. Nuclear or cellular transport is important for the survival and function of specialized cells and 14 proteins with such functions changed their levels of expression during beta-cell maturation. The Coatomer delta subunit was also up-regulated in IL-1 $\beta$ exposed rat islets [14]. Maturation into the betacell phenotype was also associated with an increased expression level of clathrin light chain, suggestive of increased capacity for exocytosis in the beta cells. This correlates well with maturation of the beta-cell phenotype, and it could be associated with increased insulin-production secreted through exocytosis in clathrin-coated vesicles [60] in the stimulatory culture condition $(11.5 \mathrm{mmol} / \mathrm{l}$ glucose $)$ used in these experiments.

We previously hypothesized that cytokines induce a race between protective and deleterious mechanisms in beta cells, and when the deleterious mechanisms prevail, beta-cell destruction and T1DM develop [4]. In addition we suggested that IL- $1 \beta$ sensitivity is an acquired trait during beta-cell maturation. This is supported by our previous studies of the two phenotypes [12]. Of the 97 proteins of changed expression patterns following beta-cell maturation some could be crucial for the required sensitivity to cytokines and resulting PiPP in response to IL-1 $\beta[14,16]$. Thus, the beta cell may "pay a price" influencing several common cellular pathways to become a highly specialized insulin-producing beta cell.

Based upon the Copenhagen Model of T1DM we attempted simple mathematical modelling of the earliest phase of the pathogenesis of T1DM [61]. Resulting from this, one could view the unperturbed beta cell as being in a parameter space characterized by dynamic stability separated by a virtual parameter surface from a parameter space characterized by dynamic instability. The closer to the parameter surface in its still dynamic instability space a beta cell is, the easier it is "pushed" into the space of dynamic instability or ongoing destruction. Maturation of a pre-beta cell (NHI-glu) into a beta-cell phenotype (NHI-ins) might position the beta cell closer to the parameter surface. When metabolically active the beta cell could, although still in the dynamic stability space, be even closer to penetrate the surface, since its sensitivity to cytokine toxicity is increased. Exposure to IL- $1 \beta$ or a mixture of cytokines might be what "pushes" beta cells through the parameter space surface and into dynamic instability and destruction. Dependent on the stimulus this could involve the interaction of several different proteins and pathways and the outcome might in part be genetically determined.

In conclusion, differentiation and maturation from a stem cell to a beta cell is a complex series of events. Future functional analyses are needed to further elucidate the role of the proteins identified in this study for the last maturation stage towards insulin production and accompanying acquired sensitivity to IL-1 $\beta$ and other cytokines. We anticipate that such knowledge could provide useful information for the design of novel and rational preventive and/or curative strate- 
gies in T1DM, both in relation to beta cell growth and differentiation as well as in inhibition of cytokine-mediated toxicity.

Acknowledgements. The technical skills and expertise of S. Munch, L. Christensen, A.M. Lorentzen, V. Mose Larsen and statistical advice from B. Carstensen are greatly appreciated. This study was in part supported by grants from the Danish Diabetes Association, Danish Medical Research council (grant no. 9902341), the Sehested Hansen Foundation, the Danish National Biotechnological Instrument Centre (DABIC), the Juvenile Diabetes Research Foundation International (JDRFI; grant no. 998005); a Focused Type 1 Research Grant from European Foundation for the Study of Diabetes/JDRFI/Novo Nordisk and a Biotech grant from the Danish Medical Research council (grant no. 9502027).

\section{References}

1. Gepts W (1965) Pathologic anatomy of the pancreas in juvenile diabetes mellitus. Diabetes 14:619-633

2. Mandrup-Poulsen T (1996) The role of interleukin-1 in the pathogenesis of IDDM. Diabetologia 39:1005-1029

3. Rabinovitch A, Suarez-Pinzon WL, Strynadka K, Lakey JR, Rajotte RV (1996) Human pancreatic islet beta-cell destruction by cytokines involves oxygen free radicals and aldehyde production. J Clin Endocrinol Metab 81:3197-3202

4. Nerup J, Mandrup-Poulsen T, Helquist S et al. (1994) On the pathogenesis of IDDM. Diabetologia 37:82-89

5. Pictet RL, Rutter WJ (1972) Development of the embryonic endocrine pancreas. Handb Physiol 1:25-66

6. Herrera PL, Huarte J, Zufferey R et al. (1994) Ablation of islet endocrine cells by targeted expression of hormonepromoter-driven toxigenes. Proc Natl Acad Sci USA 91: 12999-13003

7. Hussain MA, Lee J, Miller CP, Habener JF (1997) POU domain transcription factor brain 4 confers pancreatic alpha-cell-specific expression of the proglucagon gene through interaction with a novel proximal promoter G1 element. Mol Cell Biol 17:7186-7194

8. Oster A, Jensen J, Serup P et al. (1998) Rat endocrine pancreatic development in relation to two homeobox gene products (Pdx-1 and Nkx 6.1). J Histochem Cytochem 46: 707-715

9. Jensen J, Heller RS, Funder-Nielsen T et al. (2000) Independent development of pancreatic alpha- and beta-cells from neurogenin3-expressing precursors: a role for the Notch pathway in repression of premature differentiation. Diabetes 49:163-176

10. Madsen OD, Andersen LC, Michelsen B et al. (1988) Tissue-specific expression of transfected human insulin genes in pluripotent clonal rat lines induced during passage in vivo. Proc Natl Acad Sci USA 85:6652-6656

11. Madsen OD, Andersen LC, Serup P, Michelsen B (1989) Control of insulin gene expression in pluripotent rat islet tumor cells. Elsevier (Biomedical Division), pp 141-153

12. Nielsen K, Karlsen AE, Deckert M et al. (1999) Beta-cell maturation leads to in vitro sensitivity to cytotoxins. Diabetes 48:2324-2332

13. Andersen HU, Fey S, Mose Larsen P et al. (1997) Interleukin-1 $\beta$ induced changes in the protein expression of rat islets: a computerized database. Electropheresis 18:2091-2103

14. Mose Larsen P, Fey SJ, Larsen MR et al. (2001) Proteome analysis of interleukin-1 $\beta$-induced changes in protein expression in rat islets of Langerhans. Diabetes 50:1056-1063
15. Larsen MR, Roepstorff P (2000) Mass spectrometric identification of proteins and characterization of their posttranslational modifications in proteome analysis. Fresenius J Anal Chem 366:677-690

16. Sparre T, Christensen UB, Larsen PM et al. (2002) IL-1 beta induced protein changes in diabetes prone $\mathrm{BB}$ rat islets of Langerhans identified by proteome analysis. Diabetologia 45:1550-1561

17. Madsen OD, Larsson L-I, Rehfeld JF et al. (1986) Cloned cell lines from a tranplantable islet cell tumor are heterogeneous and express cholecystokinin in addition to islet hormones. J Cell Biol 103:2025-2034

18. Blume N, Skouv J, Larsson L-I, Holst JJ, Madsen OD (1995) Potent inhibitory effects of transplantable rat glucagonamas and insulinomas on the respective endogenous islet cells are associated with pancreatic apoptosis. J Clin Invest 96:2227-2235

19. Serup P, Petersen HV, Pedersen EE et al. (1995) The homeodomain protein IPF-1/STF-1 is expressed in a subset of islet cells and promotes rat insulin 1 gene expression dependent on an intact E1 helix-loop-helix factor binding site. Biochem J 310:997-1003

20. Jensen J, Serup P, Karlsen C, Nielsen TF, Madsen OD (1996) mRNA profiling of rat islet tumors reveals Nkx 6.1 as a $\beta$-cell-specific homeodomain transcription factor. $\mathbf{J}$ Biol Chem 271:18749-18758

21. Andersen HU, Mose Larsen P, Fey SJ et al. (1995) Two-dimensional gel electrophoresis of rat islet proteins. Interleukin-1 $\beta$-induced changes in protein expression are reduced by L-argenine depletion and nicotinamide. Diabetes 44:400-407

22. Fey SJ, Nawrocki A, Larsen MR et al. (1997) Proteome analysis of Saccharomyces cerevisiae: a methodological outline. Electrophoresis 18:1361-1372

23. Shevchenko A, Wilm M, Vorm O, Mann M (1996) Mass spectrometric sequencing of proteins silver-stained polyacrylamide gels. Anal Chem 68:850-858

24. Nawrocki A, Larsen MR, Podtelejnikov AV et al. (1998) Correlation of acidic and basic carrier ampholyte and immobilized $\mathrm{pH}$ gradient two-dimensional gel electrophoresis patterns based on mass spectrometric protein identification. Electrophoresis 19:1024-1035

25. Jensen ON, Larsen MR, Roepstorff P (1998) Mass spectrometric identification and microcharacterization of proteins from electrophoretic gels: strategies and applications. Proteins Struct Funct Genet 2:74-89

26. Offield MF, Jetton TL, Labosky PA et al. (1996) PDX-1 is required for pancreatic outgrowth and differentiation of the rostral duodenum. Development 122:983-995

27. Guz Y, Montminy MR, Stein R et al. (1995) Expression of murine STF-1, a putative insulin gene transcription factor, in beta cells of pancreas, duodenal epithelium and pancreatic exocrine and endocrine progenitors during ontogeny. Development 121:11-18

28. Nalivaeva NN, Turner AJ (2001) Post-translational modifications of proteins: acetylcholinesterase as a model system. Proteomics 1:735-747

29. Jensen ON, Podtelejnikov AV, Mann M (1997) Identification of the components of simple protein mixtures by highaccuracy peptide mass mapping and database searching. Anal Chem 69:4741-4750

30. Fey SJ, Mose Larsen P (2001) 2D or not 2D. Curr Opin Chem Biol 5:26-33

31. Sandler S, Bendtzen K, Eizirik DL et al. (1990) Metabolism and B-cell function of rat pancreatic islets exposed to human interleukin-1b in the presence of high glucose concentration. Immunol Lett 26:245-252 
32. Eizirik DL, Sandler S, Hallberg A et al. (1989) Differential sensitivity to B-cell secretagogues in cultured rat pancreatic islets exposed to human interleukin-1 $\beta$. Endocrinology 125:752-759

33. Eizirik DL, Björklund A, Welsh N (1993) Interleukin-1-induced expression of nitric oxide synthase in insulin producing cells is preceded by c-fos induction and depends on gene transcription and protein synthesis. FEBS Lett 317:62-66

34. Spinas GA, Hansen BS, Linde S et al. (1987) Interleukin-1 dose-dependently effects the biosynthsis of (pro) insulin in isolated rat islets of Lanferhans. Diabetologia 30:474-480

35. Kobayashi K, Rosenbloom C, Beaudet AL, O'Brien WE (1991) Additional mutations in argininosuccinate synthetase causing citrullinemia. Mol Biol Med 8:95-100

36. Eizirik DL, Pavlovic D (1997) Is there a role for nitricoxide in beta-cell dysfunction and damage in iddm. Diabetes Metab Res Rev 13:293-307

37. Morris SJ, Billiar T (1994) New insights into the regulation of inducible nitric oxide synthesis. Am J Physiol 266: E829-E839

38. Flodström M, Chen MC, Smismans A et al. (1999) Interleukin 1beta increases arginine accumulation and activates the citrulline-NO cycle in rat pancreatic beta cells. Cytokine 11:400-407

39. Liou AK, McCormack EA, Willison KR (1998) The chaperonin containing TCP-1 (CCT) displays a single-ring mediated disassembly and reassembly cycle. Biol Chem 379:311-319

40. Langer T, Neupert W (1994) Chaperoning mitochondrial biogenesis. In: Morimoto RI, Tissières A, Georgopoulos C (eds) The biology of heat shock proteins and molecular chaperones, 26. Cold Spring Harbor Laboratory Press, Geneva, pp 53-83

41. Gabai VL, Kabakov AE (1993) Rise in heat-shock protein level confers tolerance to energy deprivation. FEBS Lett 327:247-250

42. Scarim AL, Heitmeier MR, Corbett JA (1998) Heat shock inhibits cytokine-induced nitric oxide synthase expression by rat and human islets. Endocrinology 139:5050-5057

43. Burkart V, Liu H, Bellmann K et al. (2000) Natural resistance of human beta cells toward nitric oxide is mediated by heat shock protein 70. J Biol Chem 275:19521-19528

44. Yamagishi N, Nakayama K, Wakatsuki T, Hatayama T (2001) Characteristic changes of stress protein expression in streptozotocin-induced diabetic rats. Life Sci 69:2603-2609

45. Witte S, Villalba M, Bi K et al. (2000) Inhibition of the c-Jun N-terminal kinase/AP-1 and NF-kappa B pathways by PICOT, a novel protein kinase $\mathrm{C}$-interacting protein with a thioredoxin homology domain. J Biol Chem 275:1902-1909

46. Davis RJ (2000) Signal transduction by the JNK group of MAP kinases. Cell 103:239-252
47. Ammendrup A, Maillard A, Nielsen K et al. (2000) The cJun amino-terminal kinase pathway is preferentially activated by interleukin- 1 and controls apoptosis in differentiating pancreatic beta-cells. Diabetes 49:1468-1476

48. Ellis RE, Yuan JY, Horvitz HR (1991) Mechanisms and functions of cell death. Annu Rev Cell Biol 7:663-698

49. Schulze-Osthoff K, Ferrari D, Los M, Wesselborg S, Peter ME (1998) Apoptosis signaling by death receptors. Eur J Biochem 254:439-459

50. Delaney CA, Pavlovic D, Hoorens A, Pipeleers DG, Eizirik DL (1997) Cytokines induce deoxyribonucleic acid strand breaks and apoptosis in human pancreatic islet cells. Endocinology 138:2610-2614

51. Karlsen AE, Pavlovic D, Nielsen K et al. (2000) Interferongamma induces interleukin-1 converting enzyme expression in pancreatic islets by an interferon regulatory factor-1-dependent mechanism. J Clin Endocrinol Metab 85:830-836

52. Oberhammer FA, Hochegger K, Froschl G, Tiefenbacher R, Pavelka M (1994) Chromatin condensation during apoptosis is accompanied by degradation of lamin $\mathrm{A}+\mathrm{B}$, without enhanced activation of cdc2 kinase. J Cell Biol 126:827-837

53. Lazebnik YA, Takahashi A, Moir RD et al. (1995) Studies of the lamin proteinase reveal multiple parallel biochemical pathways during apoptotic execution. Proc Natl Acad Sci USA 92:9042-9046

54. Hodge T, Colombini M (1997) Regulation of metabolite flux through voltage-gating of VDAC channels. J Membr Biol 157:271-279

55. Shimizu S, Narita M, Tsujimoto Y (1999) Bcl-2 family proteins regulate the release of apoptogenic cytochrome $\mathrm{c}$ by the mitochondrial channel VDAC. Nature 399:483-487

56. Meister A, Anderson ME (1983) Glutathione. Annu Rev Biochem 52:711-760

57. Tiedge M, Lortz S, Drinkgern J, Lenzen S (1997) Relation between antioxidant enzyme gene-expression and antioxidative defense status of insulin-producing cells. Diabetes 46:1733-1742

58. Cavallo MG, Monetini L, Valente L et al. (1997) Glutathione protects a human insulinoma cell line from tumor necrosis factor-alpha-mediated cytotoxicity. J Clin Lab Res 27:44-47

59. Lortz S, Tiedge M, Nachtwey T et al. (2000) Protection of insulin-producing RINm5F cells against cytokine-mediated toxicity through overexpression of antioxidant enzymes. Diabetes 49:1123-1130

60. Turner MD, Arvan P (2000) Protein traffic from the secretory pathway to the endosomal system in pancreatic betacells. J Biol Chem 275:14025-14030

61. Freiesleben De Blasio B, Bak P, Pociot F, Karlsen AE, Nerup J (1999) Onset of type 1 diabetes: a dynamical instability. Diabetes 48:1677-1685 